ELORE (ISSN 1456-3010), vol. $18-1 / 2011$.

Julkaisija: Suomen Kansantietouden Tutkijain Seura ry. [http://www.elore.fi/arkisto/1_11/kolumni_saarinen.pdf]

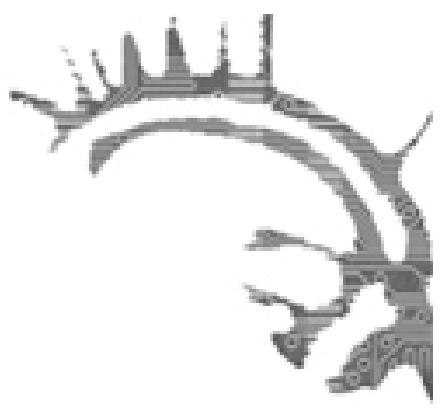

\title{
KOLUMNI: KIERTOA VERKOSSA
}

\section{$\underline{\text { Jukka Saarinen }}$}

Suomalaisen Kirjallisuuden Seuran Kansanrunousarkistoon, suomalaisen henkisen ja pääosin suullisen perinteen keskusarkistoon alkoi 1980-luvun alkupuolelta lähtien kertyä aineistoa, jonka kartuttajana ei ollut maalaista menneisyyttään muisteleva yhteinen rahvas vaan toimistoissaan paperitöitä puskevat kaupunkilaiset. Tuli humoristisia piirroksia ja kirjoituksia valokopioina, usein parodioita muodollisista ohjeista, kaavakkeista ja tiedotteista - "Urban Folklore from the Paperwork Empire", kuten Alan Dundes ja Carl L. Pagter ovat lajia kolmen vuosikymmenen takaisessa teoksessaan (1975) luonnehtineet. Kansanrunousarkiston tutkija Ulla Lipponen julkaisi vuonna 1989 antologian Siistiä sisätyötä tästä aineistosta, jota hän nimittää "kopioperinteeksi” tai "kopiohuumoriksi", koska aineiston leviämisen takana ja edellytyksenä oli valokopiointitekniikan jokapäiväistyminen toimistoissa.

"Paperitöistä" Lipponen kirjoittaa: "Sähköiseen viestintään perustuva paperiton konttori on ehkä jo huomisen todellisuutta, mutta vielä tänä päivänä kuuluvat lomakkeet, muistiot, kirjeet, tiedotukset, anomukset ja selvitykset toimistoväen arkipäivään" (Lipponen 1989, 60). Paperiton konttori ei ole todellisuutta vielä tänäänkään, tuotamme A4-saastetta töissä varmaankin enemmän kuin koskaan ennen. Mutta perinne, joka aiemmin papereina kulki, muuntui jo melko pian tuon jälkeen sähköiseksi: sähköpostiin ja internetiin. SKS sai sähköpostin vuonna 1997. Havaittuaan kiertoviestiaineiston olemassaolon Ulla Lipponen rakensi kollegoista, tuttavista, opiskelijoista ja aiemmista keruista tuntemistaan henkilöistä keruuverkon. Hän kyseli, vastaanotti, kommentoi ja tallensi verkon lähettämiä viestejä. Ensimmäisenä vuonna viestejä kertyi 12 , seuraavina muutama sata kunnes 2000-luvun alussa määrä vakiintui vuosittain parintuhannen viestin tasolle. Keruu päättyi vuonna 2006. Kymmenen vuoden aikana kertyi noin 15000 viestiä, tiedostoiksi tallennettuina ja liitetiedostoineen liki 30000 tiedostoa. Vastaajia oli 180, joista osa on toimittanut muutaman viestin, monet satoja.

Millaisen perinnelajin tämä aineisto oikein muodostaa? Vastaajat nimittävät sitä 
Jukka Saarinen: Kolumni: Kiertoa verkossa

usein sähköpostihuumoriksi, vaikka läheskään kaikki viestit eivät ole hauskoiksi tarkoitettuja. Tavallisia nimityksiä ovat myös sähköpostiperinne tai kiertoviestit, joilla luonnehditaan aineiston välitystapaa ja alkuperää: se kulkee sähköpostissa, on anonyymia, muualta saatua, kiertävää. Vaikka joukossa on myös tekijyydeltään tunnettua tavaraa kuten pilapiirroksia ja sarjakuvastrippejä, viestien lähettäjät ja alkuunpanijat eivät ole niiden tekijöitä: joku on ne skannannut tai kopioinut ja laittanut kiertoon. Suomalaisten kiertoviestien suosikki esimerkiksi on Viivi ja Wagner, joka liittyy kiertoviestien tavallisimpaan aihepiiriin, parisuhteeseen.

Varsin yleinen kiertoviesti laitetaan Dalai Laman piikkiin:

Tässä lyhyt viesti luettavaksesi. Nauti siitä! Tämän viestin Dalai Lama on antanut tälle vuosituhannelle. Lukeminen vie vain muutaman sekunnin. Lähetä tämä eteenpäin 96 tunnin sisällä siitä, kun luit tämän. Saat iloisia yllätyksiä...

Tätä seuraa lista elämänohjeita kuten "Ota huomioon, että Suuri Rakkaus ja Suuret Saavutukset sisältävät myös suuria riskejä". Amerikkalaisen Snopeş.com -sivuston mukaan viesti ei kuitenkaan ole lähtenyt Dalai Laman toimesta liikkeelle. Se on itse asiassa lyhennetty versio paljon aikaisemmasta viestistä, jota on levitetty "nepalilaisen" tai "japanilaisen" tai " havaijilaisen" onnentoteemin nimellä. Moni varmaan muistaa näitä kirjoitusmerkeillä piirrettyjä toteemeja, enkeleitä, sydämiä viime vuosisadan lopulta, jotka sähköpostiohjelmien kehittymisen myötä hiljalleen ovat kuihtuneet pois.

Snopes.com ilmoittaa olevansa "the definitive Internet reference source for urban legends, folklore, myths, rumors, and misinformation". Sivuilta löytyykin taustat hyvin monelle kiertoviestien jutuille. Aika moni on varmaan nähnyt kuva presidentti Bushista kouluvierailulla kirja väärinpäin käsissään - kuvamanipulaatio, josta Şnopeş.com esittää alkuperäisen kuvan. Moni on myös varmaan järkyttynyt tekstistä, joka kertoo bonsai-kissanpentujen kasvatuksesta, ja lähettänyt viestiä vetoomuksena eteenpäin - juttu perustuu alkujaan pilasivustoon, joka on jossain vaiheessa otettu liian vakavasti. Esimerkkejä on leegioittain. Kovin helposti menemme halpaan, kun olosuhteet ovat oikeat. Toisaalta huumorissa ei totuus ehkä sittenkään ole aivan välttämätöntä: viesteissä kiertäneet George W. Bushin tiliin laitetut lausumat eivät ehkä kaikki ole aitoja mutta silti huvittavia. Sekä Bushin että hänen vastaehdokkaansa John Kerryn väitetään esimerkiksi sanoneen vaalivuonna 2004: "If we don't succeed, we run the risk of failure". Ovatkohan kaikki Matti Nykäsen sanonnatkaan autenttisia?

Viestien formulointi ketjukirjeiksi on yleinen menettely tässä perinteessä. Käytetään lajityypillisiä retorisia keinoja: pitkälle ulottuvaan alkuperään vetoamista, jatkokehotuksia, palkinnon lupauksia ja ketjun katkaisemisen seurauksilla uhkailemisia. Muotoilua ei sovelleta pelkästään vakaviin vetoomuksiin ja onnea tuoviin elämänohjeisiin, vaan melkein mitä vaan voidaan siihen upottaa. "Suklaa on vihannes", todistelee humoristinen PowerPoint-esitys ja kehottaa lopuksi: "Lähetä tämä viesti 4 henkilölle, niin laihdut 2 kiloa... Mikäli et tee tälle viestille mitään, lihot silmänräpäyksessä 10 kiloa." Kiertoviesti onkin kuvaava nimitys tälle aineistolle: osa siitä on humoristista, osa vakavampaa, osa siltä väliltä. Kuvat oudoista, erikoisista ilmiöistä ja sattumista ovat 
tavallisia: erikoisia tatuointeja ja lävistyksiä, rivoja luontokuvia puiden ulokkeista ja halkeamista, erikoisia automaalauksia, kuvia ikävistä töistä otsikon "lopeta tuo töistäsi valittaminen" alla ja muita. Kuvat hämmästyttävät, huvittavat, iljettävät, pelottavat, katsojan mukaan.

Pääosin kiertoviestit ovat kuitenkin humoristisia ja lisäksi vanhan kopioperinteen jatkajia. Dundesin ja Pagterin antologioita lukiessa huomaa jatkuvasti, miten vanhaa juttua on kierrätetty sellaisenaan, käännettynä tai vähän muokattuna vuosikymmenien ajan. Vain väline on vaihtunut. Joskus törmää uudelleenrunoiluun: vanha idea on muutettu uuteen tilanteeseen sopivaksi. Vanhempien sukupolvien päivittely nykyajan lasten ja nuorten elämästä ja ennen kaikkea sen helppoudesta on jo ihan klisee. Suomenkielinen kuvasarja "Onnellinen lapsuus" kuvaillaan asioita, joita ennen ei ollut ja mitä oli sen sijasta:

Ei ollut mitään LAPSITURVALUKKOJA pistorasioissa, autonovissa, lääkepulloissa eikä kemiallisissa kodin puhdistusaineissa... Meillä ei ollut Playstation-, Nintendo 64-, X-Box- ja muita videopelejä, 99 kaapelikanavaa, videonauhuria, Dolby Surroundia, kännyköitä, tietokoneita eikä chatroomeja tai e-baytä Internetissä vain ystäviä.

Ulf Palmenfeltin ruotsalaisessa antologiassa (1986) esitetty varhaisempi valokopio "En faders undran" puhuttelee niitä, jotka ovat syntyneet "paarmuskan" avulla ilman äitiysrahaa ja kirjoittaneet koulussa omille rihvelitauluille. Vaikka muotoilu ja yksityiskohdat ovat erilaiset, perusidea on sama: "Hur tusen kunde vi klara oss?" - "Miten olemme pystyneet pitämään itsemme elossa näinkin kauan?" Teksti on erilainen mutta asetelma ikiaikainen.

Huumoriviestien yleisin aihe on parisuhde, tai parisuhde ja seksi. Tässä aineistossa naiset todellakin ovat Venuksesta ja miehet ... ihan jostain muualta. Erilaiset vitsit, listat, vertailut, sanastot kuvat ja muut sisältävät molempien näkökulmia mutta aina toisilleen vastakkaisina ja kilpailevina. Jos naisilla on "10 syytä miksi kurkku on parempi kuin mies", miehillä on vastaavasti "10 syytä miksi olut on parempi kuin nainen". Jotkut viestit ovat kiinnostavan monitulkintaisia. Kuvia vuoden miehestä ("Man of the Year") voi katsella, ehkei ihan tosissaan mutta kuitenkin, joko ihaillen miesnäkökulmasta tai paheksuen naisnäkökulmasta. Kuvasarjassa on vain muutama vaihteleva kuva (googlaa "man of the year"!): nainen kantaa valtavaa risukasaa, mies kulkee joutilaana vieressä; nainen raahaa kuutta kaljakoria, mies pulloa; mies on ottanut polkupyöränsä telttaan, nainen värjöttelee ulkopuolella. Ovatko kuvat autenttisia, lavastettuja vai sattumanlaukauksia - ehkei kuvien miehillä ja naisilla ole mitään tekemistä keskenään? Tätä en tiedä. Olennaista kuitenkin on, että näemme niissä mitä uskomme ja tahdomme nähdä.

Perinteisten viestien joukkoon ja niiden mallille syntyy uutta aineistoa ajankohtaisista aiheista. World Trade Centerin terrori-isku 11.9.2001, Lahden MM-hiihtojen doping -skandaali 2001 synnyttivät aineistoryöpyn, joka dokumentoitui laajasti keruun aineistossa; niitä on myös jo tutkittu (Kiiveri 2004; Lifländer 2004). Uusi tekninen ympäristö myös mahdollisti asioita, jotka ennen olivat hankalampia toteuttaa. Kier- 
Jukka Saarinen: Kolumni: Kiertoa verkossa

toviestien mukana kulkee sekä aitoja että manipuloituja valokuvia, videoleikkeitä, pelejä sisältäviä ohjelmatiedostoja. Tosin varsinaisten ohjelmien osuus putosi nopeasti 2000-luvun alun jälkeen yritysten ja laitosten tietoturvakäytänteiden tiukennuttua. Tiedostomuotojen kirjo on suuri: pelkkää tekstiä, PowerPoint-esityksiä, Word-tiedostoja, JPG-kuvia, Excel-taulukoita, erilaisia videotiedostoja ja paljon muita. Tekstitiedostot, PowerPointit ja JPG-kuvat muodostavat kuitenkin sähköpostiperinteen pääosan. Arkistoinnin kannalta tilanne on haastava, koska sähköpostitileillä tiedostoja ei voi säilöä. Sekä viestitekstit että liitetiedostot pitää konvertoida erillisiksi tiedostoiksi, ja samalla säilyttää yhteys niiden välillä. (Tämä oli minun tehtäväni ja yhteyteni tähän aineistoon.)

PowerPoint -esitykset, jotka me kaikki tunnemme luentojen, seminaarien ja esittelytilaisuuksien välttämättöminä osina, alkoivat voimakkaasti yleistyä kiertoviestien liitteinä 2000-luvun alussa. PowerPoint mahdollistaa kuvien esittämisen määräjärjestyksessä, yhdistämisen tekstiin ja esittämisen vähän kuin suullisesti. Lukija ei voi helposti hyppiä kohdasta toiseen, kurkistella etukäteen mitä tapahtuu vaan joutuu kärsivällisesti katsomaan diakuvan kerrallaan tuskaillen sana kerrallaan näytölle ilmestyvää ja viipyilevää tekstiä. Jutun lopun yllätyksellisyyttä, vitsin huippua on helppo korostaa. PowerPointiin voi yhdistää myös äänen. Jos viestin lähettäjä kehottaa "ja äänet sitten pällle", viimeiseen diaan on todennäköisesti kätketty joku rääkäisy yhdistettynä apinan tai muun vastaavan kuvaan. Tuon kehotuksen jälkeen minä ainakin väännän äänet pois!

Parisuhteen ja seksin jälkeen kiertoviestien tavallisin teema on työ. Kiertoviestien työpaikat ovat monimutkaisia ja kieroutuneita organisaatioita, joissa työntekijät puurtavat ja johtajat palkitaan. "Work hard an you shall be rewarded" julistaa piirroksessa ruuvin lävistämä mies jo vanhassa kopioperinteessä. PowerPointilla toteutettu palkkakeskustelu päätyy aina toteamukseen "Palkkatasosi on nyt vahvistettu. Palkkasi pysyy ensi vuonna samansuuruisena". Kyselyyn vastaaja ei pysty klikkaamaan vaihtoehtoa Ei, koska tämä vaihtoehdon laatikko pakenee heti, kun hiiri on sen kohdalla. Samalla systeemillä on toteutettu myös lomalaskuri, jonka kysymykseen "Aiotko pitää tämän lomakauden aikana lomaa?" on mahdotonta vastata Kyllä ja vastaaja joutuu lopulta vahvistamaan lomapäiviensä poiston. "Kiitämme sinua osoittamastasi uskollisuudestasi ja avokäteisyydestäsi! Henkilöstöpäällikkö". Kun jutun teknisen hyperlinkitykseen perustuvan toimintaidean keksii, uusien vastaavien kyselyiden tekeminen on suhteellisen yksinkertaista.

Kiertoviestejä on välitetty ja luettu erityisesti työsähköposteilla ja -koneilla. Kiertoviestit viittaavat joskus tähän liittyvään luvattomuuden tuntuun. Excel-muotoiseen "eläkelaskuriin" pyydetään täyttämään oma nimi, ikä ja työnantaja. Kun sen jälkeen kirjoittaa "Start" (viittaa viestin ulkomaiseen alkuperään), ilmestyy taulukkoon teksti:

Jukka, LOPETA HÖLMÖILY!!

EI SINUN TARVITSE JOKAISTA HUPIVIESTIÄ AVATA, JOITA SINULLE JATKUVASTI LÄHETETÄÄN!

SKS ei maksa sinulle näiden viestien lukemisesta.

Herran tähden, olet 52 -vuotias!

Kasva aikuiseksi ja ala käyttäytyä!

Allekirjoitus: SKS, johtoporras 
Väärässä ovat. Minun täytyi avata jokainen hupiviesti, ihan palkkatyönä. Tosin tähän viestiin on olemassa sitä vastakkaisesti kommentoiva samanlainen laskuri, jonka tuottama teksti alkaa "Jukka, nyt justiinsa terassille ja sitten kovaa kyytiä kotia pötköttämään. Lopeta se sähköpostin lukeminen, ei ne viestit silti mihinkään katoa..."

Kiertoviestien kierto tuntuu pysähtyneen. Ulla Lipposen lopetettua keruutyön muutamat kollegat ja tuttavat ovat halunneet vielä tarjota viestejä tallennettaviksi. Ehdin tallentaa nelisensataa viestiä parin vuoden aikana ilman mitään keruuverkkoa, mutta reiluun vuoteen kukaan ei ole tarjonnutkaan mitään. Paras tapa herättää perinne henkiin on julistaa se kuolleeksi. Aina löytyy jostain se viimeinen runonlaulaja. Onko kiertoviestien välitys todella jo kadonnut ja mitä niille on tapahtunut? Ovatko kaikki ruvenneet suoraan internetin hupisivustojen ja sosiaalisen median käyttäjiksi? Facebookissa ja YouTubessako huumori, huhut ja vetoomukset nyt pesivät? Huhtikuussa 2010 islantilaisen tulivuoren purkaus levitti valtavat määrät tuhkaa ilmakehään ja lamautti pohjoisen Euroopan lentoliikenteen. Facebookiin syntyi ryhmä ’’U.KO.

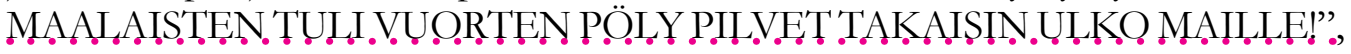
johon liittyi hyvin nopeassa tahdissa melkein 50000 jäsentä. Seinäkirjoituksia tuli alussa muutaman sekunnin välein ja kirjoittajat sisäistivät nopeasti säännöt: kirjoita virheellisesti, yhdyssanat erikseen ja suurin kirjaimin. Jos eivät sisäistäneet, heitä oikaistiin nopeasti. Sosiaalinen kontrolli toimi. Ryhmä parodioi maahanmuuttokriittistä keskustelufoorumia, mutta kuinkahan suuri osa liittyneistä on koskaan seurannut tai edes nähnyt näiden ryhmien kirjoituksia? Parodian kohteen tarkka tuntemus ei ole välttämätöntä, muodostuneiden perinnenormien noudattaminen taas on.

Kiertoviestejä tulivuorenpurkaus olisi varmaan myös synnyttänyt, mutta muoto olisi ollut erilainen. Ryhmän kuvissa on paljon sellaisia, jotka olisivat kiertäneet viesteissä, jos Eyjafjallajökullin tulivuorenpurkaus olisi tapahtunut viisi vuotta aiemmin. Sosiaalisessa mediassa suositellaan sivustoja, tykätään, perustetaan ryhmiä, luodaan osin samanlaista "perinnettä" kuin kiertoviesteissäkin. Tieto välittyy kuitenkin eri tavalla: julkisesti, ei lähettäjän ja vastaanottajan kesken. Merkitsisikö moni tykkäävänsä sivustosta, jolla on kuvia koomisiin asentoihin sammuneista kanssaihmisistämme ('Puistojoogaa")? Kun kuvasarjan saa kiertoviestin liitteenä, kuville voi ihan vapaasti naureskella ilman muiden paheksunnan pelkoa.

Kiertoviestien sisällöt ovat tuskin mihinkään kadonneet eivätkä ne koskaan ole olleetkaan pelkästään kiertoviestien omaisuutta. Samaa aineistoa on aina ollut kopiohuumorissa, kirjoissa lehdissä, hauskoissa t-paidoissa ja mukeissa, myytävissä huoneentauluissa. Kiertoviestitkin viittasivat usein internetin sivustoihin, niiden sisältö on elänyt sähköistä kaksoiselämää niin viesteissä kuin netissä. Suurin osa linkeistä ei kylläkään enää toimi, mutta se ei tarkoita, että ne olisivat kadonneet. Ne ovat vain muuttaneet, muuttuneet ja sulautuneet osaksi tietoverkkojen maailmaa.

Ulla Lipposen keräämän aineiston tekninen arkistointi on loppusuoralla mutta sisällönanalyysi ja luettelointi aloittamatta. Kansanrunousarkisto toivoo saattavansa materiaalin pian tutkimuskäyttöön. Aineistossa on tosin joitain käyttörajoituksia. Olisikin toivottavaa saada aikaan luettelo tai antologia, joka kertoisi sekä tämän materiaalin moninaisuudesta että sen painopisteistä. Ulla Lipposen kiertoviestiaineisto on laaja ja kattaa sen kymmenvuotiskauden, jolloin suomalaiset tottuivat sähköpostiin ja siitä tuli tärkeä osa heidän elämäänsä. 
Jukka Saarinen: Kolumni: Kiertoa verkossa

\section{KiRJALlisuUS}

DUNDES, ALAN \& PAGTER, CARL R.1975: Work Hard and You Shall Be Rewarded. Urban Folklore from the Paperwork. Empire. Bloomington \& London: Indiana University Press.

DUNDES, ALAN \& PAGTER, CARL R. 1987: When You're up to Your Ass in Alligators... More Urban Folklore from the Paperwork Empire. Detroit: Wayne State University Press.

DUNDES, ALAN \& PAGTER, CARL R. 1996: Sometimes the Dragon Wins. Yet More Urban Folklore from the Paperwork Empire. Syracuse, New York: Syracuse University Press.

KIIVERI, MIRVA 2004: Länsimaiset ennakkolunlot ja toiseuden stereotypiat WTC-sähköpostiperinteessä. Folkloristiikan pro gradu -tutkielma. Helsinki: Helsingin yliopisto.

LIFLÄNDER, HANNA-MARIA 2004: Luovuta ajoissa: Kilpahiihdon dopingskandaalin bumoristinen käsittely internetissä. Folkloristiikan pro gradu -tutkielma. Helsinki: Helsingin yliopisto.

LIPPONEN, ULLA 1989: Sïstiä sisätyötä. Kopiobuumoria. Helsinki: Suomalaisen Kirjallisuuden Seura.

PALMENFELT, ULF 1986: Folkhumor i fotostat. Stockholm: Bokförlaget Prisma.

SNOPES.C.QM. Urban Legends Reference Pages. [online] < http://www.snopes.com/> [13.3.2011.]

FK Jukka Saarinen toimii kokoelmapäällikkönä Suomalaisen Kirjallisuuden Seuran kansanrunousarkistossa. 